\title{
DELMIRA, ALFONSINA, JUANA Y GABRIELA: INTERTEXTUALIDADES
}

\author{
Mirta Fernández dos Santos \\ UNED \\ mdossanto2@alumno.uned.es
}

\section{RESUMEN}

Por su condición de precursora de la poesía escrita por mujeres en el contexto literario rioplatense de comienzos del siglo XX, Delmira Agustini ha sido señalada en muchas ocasiones por la crítica como un referente incuestionable para las poetas que, en el mismo ambiente cultural, le tomaron el relevo: Alfonsina Storni, Juana de Ibarbourou y Gabriela Mistral. Pero, más allá de las concomitancias apuntadas por los críticos en lo que respecta a las influencias mutuas existentes entre las tres grandes poetas del Cono Sur, bajo el postulado previo de Delmira, todas ellas se refirieron en algún momento de sus trayectorias literarias al carácter tutelar de la poética de la autora de Los cálices vacíos. En ese sentido, el objetivo de este artículo es dar a conocer algunos documentos inéditos y recuperar otros poco difundidos a través de los cuales Storni, Ibarbourou y Mistral ilustran, en primera persona, el influjo ejercido por Agustini en la configuración de sus respectivas identidades poéticas.

Palabras Clave: poesía; mujeres; feminismo; intertextualidad; Cono Sur.

\section{Abstract}

Delmira Agustini has been considered by critics a precursor of poetry written by women in the Río de la Plata literary context at the beginning of the 20th century, and also as an undeniable reference for other Latin American women poets: Alfonsina Storni, Juana de Ibarbourou and Gabriela Mistral. In addition to the coincidences identified regarding mutual influences that exist among the three big women poets of the Southern Cone, each of them wrote about Delmira Agustini's tutelage. Thus, the aim of this paper is to unveil some unpublished documents and to retrieve others that are not widely read. In these writings, I will demonstrate how Storni, Ibarbourou and Mistral reveal the influence exerted by Agustini in shaping their poetic identities.

KEYwORDS: poetry; women; feminism; intertextuality; Southern Cone. 


\section{Delmira Agustini es la santa laica de las mujeres latinas que hacen poesía. Juana de Ibarbourou}

A lo largo de los años, muchos especialistas han puesto de manifiesto el carácter tutelar de la poética de Delmira Agustini en relación con la obra de la argentina Alfonsina Storni, la uruguaya Juana de Ibarbourou y la chilena Gabriela Mistral, a las que siempre se ha considerado sus más directas y fieles sucesoras.

Así, el crítico uruguayo Jorge Arbeleche en su artículo «Tres mujeres tristes» (1998), dedicado a Storni, Ibarbourou y Mistral, a propósito de las ponencias impartidas por las tres escritoras en un ciclo de conferencias que se realizaron en el Instituto preuniversitario Vásquez Acevedo de Montevideo en enero de 1938, con motivo de la celebración del curso latinoamericano de vacaciones, no duda en señalar el papel precursor de Agustini en la trayectoria de sus discípulas:

Son tres mujeres unidas en la historia de la poesía hispanoamericana bajo la tutela de la adelantada Delmira Agustini, la más agónica, que fue destruida por la red de prejuicios del Uruguay de 1914. Las tres, sufrientes y heroicas, pagaron con su vida o su felicidad la entrega a la Poesía. (Arbeleche, 1998, s/p)

No obstante, si bien existen similitudes en sus respectivos itinerarios literarios, como la sexualización de su palabra, que las convirtió en estandarte de un feminismo combativo que no tardó en despuntar en el Río de la Plata, y el hecho de que todas ellas cultivaran, de alguna manera, los temas universales de la poesía (el concepto de Dios, el amor, la vida y la muerte), las diferencias entre ellas son también muy significativas. Para empezar, como apunta Dolores Koch, la imagen que proyectan de sí mismas es muy distinta:

Delmira Agustini, exultante en su belleza y su sensualidad, es la amante ideal; Juana de Ibarbourou, diosa serena y amante, sin «vergüenza del sexo sin celajes», es la esposa por excelencia; Alfonsina Storni, mujer libre e intelectual, frustrada por el hombre y la sociedad, es la rebelde feminista, y Gabriela Mistral, la que supo sublimar sus anhelos truncos, es la madre, la figura más universal. (Koch, 1985: 724)

Aunque las cuatro nacieron en un intervalo de seis años (1886-1892) $)^{1}$ en el Cono Sur, a Delmira le correspondió habitar un espacio nuevo, el de la escritura femenina, prácticamente sola $^{2}$, mientras que las otras tres grandes poetas sudamericanas, con sus afinidades y desemejanzas, pudieron compartir ese pesado lastre.

${ }^{1}$ Delmira Agustini nació en 1886; Gabriela Mistral, en 1889; y Alfonsina Storni y Juana de Ibarbourou, en 1892 .

${ }^{2}$ Cabría mencionar, por supuesto, a modo de excepción, a María Eugenia Vaz Ferreira como coetánea de Delmira Agustini. No obstante, como sabemos, su trayectoria fue bastante más errática que la de la autora de Los cálices vacíos, y bastante menos prolífica. Además, en última estancia, a pesar de sus conocidas extra- 
En ese sentido, la falta de apoyo moral que vivenció Delmira, aliada al hecho de carecer de referentes femeninos legitimados en el terreno de la literatura, provocó efectos devastadores en su escritura poética, como resultado de la indiferencia que percibía a su alrededor. Ella aspiraba a lograr la perfecta compenetración física e intelectual con un hombre superior (el superhombre nietzscheano) para crear una raza nueva libre de prejuicios. Pero sus ansias chocaban una y otra vez contra un recio muro de incomprensión: su credo lírico era, a finales del siglo XIX, demasiado transgresor y su sensualidad demasiado expuesta como para que la sociedad rioplatense la aceptara sin reparos.

En cuanto a Alfonsina Storni, según Koch (1985), su trayectoria literaria comenzó en el punto en el que la de Delmira se interrumpió. En el lenguaje poético de Storni se advierte una profunda conciencia feminista y una compleja animadversión hacia el hombre, no exenta de conflictos ya que, al mismo tiempo que se consideraba superior a él, se sentía incapaz de escapar del influjo y el atractivo masculinos. De ahí que su poesía destile gotas de amargura e insatisfacción:

Hombre pequeñito, hombre pequeñito,

Suelta a tu canario...

Yo soy el canario, hombre pequeñito.

Déjame saltar ${ }^{3}$.

Si bien el poema anterior ya deja entrever el enfrentamiento directo de la voz lírica femenina al varón al que dedica la composición, probablemente el texto de Storni que mejor refleja sus reivindicaciones feministas y el nuevo papel que la mujer debía ocupar en la sociedad es el célebre y frecuentemente antologado «Tú me quieres blanca», en el que la voz poética femenina le reprocha al hombre su moral de doble rasero, al exigir de la ella una decencia comportamental en sus relaciones con el otro sexo que él mismo no practicaba ni representaba:

Tú me quieres alba,

Me quieres de espumas,

Me quieres de nácar.

Que sea azucena

Sobre todas, casta.

De perfume tenue.

Corola cerrada ${ }^{4}$.

\footnotetext{
vagancias, el lenguaje poético de María Eugenia en su momento no supuso un escándalo tan sonado para la sociedad uruguaya finisecular como el de Agustini.

${ }^{3}$ Storni, Alfonsina, «Hombre pequeñito», disponible en http://cvc.cervantes.es/actcult/storni/antologia/antologia06.htm.

${ }^{4}$ Storni, Alfonsina, «Tú me quieres blanca», disponible en http://cvc.cervantes.es/actcult/storni/antologia/ antologia03.htm.
} 
En ambas composiciones Storni apela, de forma incluso más abierta que Agustini, al innovador rol de la mujer como sujeto activo de las relaciones amorosas: «[...] la mujer que desea, que toma iniciativas eróticas, que recorre con su mirada la hermosura del cuerpo masculino y que lo dice desde su propio cuerpo» (Blas de Matamoro) ${ }^{5}$.

Por su parte, la visión poética de Juana de Ibarbourou, otra uruguaya ilustre, que llegó a ser aclamada como «Juana de América», apelativo que la universalizó, se caracteriza por su carácter placentero, armonioso y panteísta: «Se entrega en sus versos vital, desnuda y casta a la vez, sin complicaciones ni desmesurados anhelos» (Koch, 1985: 727). Se puede considerar, de hecho, que el talante sencillo de su poética es la base del enorme éxito que cosechó:

Parte de su seducción, para los lectores de esa época, posiblemente fueran la pasión, sencillez y melancolía, conjugados en una poesía de la cual ella es única poseedora y dueña, todo esto totalmente opuesto a lo que se denomina intelectualidad femenina. Enamorada de la vida misma, de toda la naturaleza pura y de todos los minutos, trajo alegría a la literatura en un momento en que ésta la necesitaba, desparramando poemas inyectados de vida, belleza y juventud, plenos de ansias de amar y ser amada [...] (Pueyrredón, 1978: 135)

En su obra se intuyen varias fases que se identifican, en cierto modo, con las etapas vitales del ser humano. Así, el crítico Enrique Anderson Imbert, citado por Victoria Pueyrredón (1978: 135), establece un paralelismo entre la producción poética de Ibarbourou y las cuatro estaciones del año que, a su vez, representan los ciclos vitales: «Las lenguas de diamante (1919) fue la iniciación de la vida en una mañana de primavera; Raíz salvaje (1920), la juventud de la vida en un mediodía estival; La rosa de los vientos (1930), la madurez en un atardecer de otoño; y Perdida (1950), la vejez en una noche invernal».

Una de las preocupaciones fundamentales que se percibe en la lírica de Juana de Ibarbourou es el miedo al declive de los cuerpos por el paso inexorable del tiempo. Ante esta realidad, la poeta se muestra retadora, en una primera etapa, jocosa y narcisista, en la plenitud de su belleza y vigor físicos, y, finalmente, decepcionada, vencida y sola en el ocaso de su vida. En ese sentido, la obstinación que emana de su poderosa femineidad se manifiesta fundamentalmente en los poemas que integran Las lenguas de diamante (1919), de los cuales el afamado soneto «Rebelde» constituye un ejemplo paradigmático de enfrentamiento a la muerte:

Caronte: yo seré un escándalo en tu barca.

Mientras las otras sombras recen, giman o lloren,

Y bajo tus miradas de siniestro patriarca

Las tímidas y tristes, en bajo acento oren,

Yo iré como una alondra cantando por el río

Y llevaré a tu barca mi perfume salvaje,

${ }^{5}$ «Alfonsina, la precursora». Artículo sin fecha, disponible en http://cvc.cervantes.es/actcult/storni/acerca/ matamoro.htm. 
E irradiaré en las ondas del arroyo sombrío

Como una azul linterna que alumbrara en el viaje.

Por más que tú no quieras, por más guiños siniestros

Que me hagan tus dos ojos, en el terror maestros,

Caronte, yo en tu barca seré como un escándalo.

Y extenuada de sombra, de valor y de frío,

Cuando quieras dejarme a la orilla del río

Me bajarán tus brazos cual conquista de vándalo ${ }^{6}$.

Mercedes Pinto (1935), en un fervoroso artículo dedicado a cuatro poetisas uruguayas (Agustini, Ibarbourou, Vaz Ferreira y Luisi), describe así el alcance del soneto que acabamos de transcribir:

[...] vemos con visión destacada en las tinieblas de toda una poesía de siglos, enlutada y trágica de desesperaciones deleznables, esa «barca de Caronte», dramática en su viaje a lo indescifrable, cargada de almas vencidas y claudicantes que gimen imploradoras o se deshacen en lágrimas estériles, cómo se alza la figura rotunda de esa criatura «escándalo» de plenitud, rebosante de vitalidad inextinguible, cómo se deja conducir más allá de las sombras, más allá del horror, de la descomposición y del misterio, como brillante espada entre la niebla, que rasga y descompone con su risa jocunda y temeraria. (Pinto, 1935: 51-52)

En términos de intertextualidad, Pablo Rocca (2011: 64) señala que el soneto «Rebelde» de Juana de Ibarbourou evoca otro de Delmira Agustini, «El intruso» ${ }^{7}$, por su forma (ambos son sonetos, se abren con un vocativo y se caracterizan por su rica adjetivación), pero también por la recuperación de ciertas ideas, como la omnipresencia de Eros y Thánatos, cuya conjunción se resuelve de forma distinta en las dos composiciones: «En "El intruso" Eros derrota a Thánatos; en "Rebelde", Thánatos es retado por el Eros juvenil, y al fin el primero se impone por su fuerza, "como un vándalo"» (Rocca, 2011: 66).

En definitiva, Juana de Ibarbourou supo encontrar la fórmula para brillar con luz propia en el ámbito de la poesía femenina hispanoamericana de las primeras décadas del siglo XX, sin estridencias, con una lírica de gran amplitud temática, pautada por el equilibrio entre el contenido y la forma.

Del mismo modo, Gabriela Mistral ${ }^{8}$ logra también la plenitud, si bien lo hace a través de un procedimiento distinto: «Todo en el mundo le atrae, todo en el mundo le duele» (Koch, 1985: 728).

De las cuatro poetas del Cono Sur a las que nos venimos refiriendo, Mistral es probablemente la figura más universal debido, fundamentalmente, a la concesión del premio Nobel, que

\footnotetext{
${ }^{6}$ De Ibarbourou, Juana, «Rebelde», disponible en http://amediavoz.com/ibarbourou.htm\#REBELDE.

7 Agustini, Delmira, «El intruso», disponible en http://cvc.cervantes.es/literatura/escritores/agustini/antologia/ intruso.htm.

${ }^{8}$ Gabriela Mistral fue el seudónimo definitivo que adoptó la poeta chilena Lucila de María del Perpetuo Socorro Godoy Alcayaga, nacida en la localidad de Vicuña en 1889.
} 
le fue atribuido en 1945, en palabras del portavoz de la Academia sueca, «por su poesía lírica, inspirada por poderosas emociones que han hecho de su nombre un símbolo de las aspiraciones idealistas de todo el mundo latinoamericano» ${ }^{9}$. Mucho antes de recibir este importante galardón, ya había obtenido otro importante reconocimiento: el primer premio en los Juegos florales realizados en Santiago de Chile en 1914, por «Los sonetos de la muerte», una serie de poemas inspirados en el repentino fallecimiento de su prometido. Este codiciado premio contribuyó en gran medida a destacarla como una de las autoras más prometedoras de la poesía sudamericana.

En los versos de Mistral, a diferencia de lo que ocurre en la lírica de las otras tres poetas mencionadas, no se atisban siquiera destellos de erotismo. El amor abstracto, en cambio, hace frecuentemente acto de presencia en sus poemas, pero se trata de un sentimiento sublimado, con una vocación casi cósmica. Como señala acertadamente Koch (1985: 729), «al no poder amar al hombre en particular, amó a la humanidad».

Mistral compartió con Storni un profundo sentimiento feminista, lo que las distingue de las dos poetas uruguayas: pese a lo iconoclasta de su canto poético, Agustini ni fue feminista ni pretendió ser precursora del feminismo, contrariamente a lo que muchos críticos han defendido en los últimos años. Desde luego, tampoco lo fue Juana de Ibarbourou, ya que nunca sintió la necesidad de rebelarse como mujer ante la sociedad en la que le tocó vivir y crear.

Gabriela, en cambio, sí fue una voz reivindicativa, no solo en lo concerniente a los derechos de las mujeres, sino también en lo tocante al pacifismo y a la causa americanista:

El hecho de ser pacifista, libertaria y feminista le causó problemas. Salió en defensa de Sandino, cuando Estados Unidos amenazaba invadir Nicaragua; luchó por los derechos humanos, el voto de la mujer y la igualdad con el hombre, y pidió al sector femenino que se instruyera para no ser considerada objeto de la sociedad. (Sergio Macías) ${ }^{10}$.

Aparte de las ya citadas, otros rasgos que singularizan la poética Mistral y la vuelven atemporal son la exaltación de la maternidad (una maternidad que en ella se vio frustrada); la transgresión religiosa, a menudo vinculada al dolor y a la muerte; y una aplaudida capacidad de armonizar dualidades opuestas y, a menudo, aparentemente irreconciliables. Varios de estos temas se coadunan, además de en otros poemas, en sus conocidos y reconocidos «Sonetos de la muerte»:

\section{I}

Del nicho helado en que los hombres te pusieron,

Te bajaré a la tierra humilde y soleada.

Que he de dormirme en ella los hombres no supieron,

Y que hemos de soñar sobre la misma almohada.

${ }^{9}$ Cita recuperada del artículo «Gabriela Mistral, poeta, diplomática y Nobel de Literatura» publicado en la edición digital del diario El Heraldo de Honduras del día 9 de enero de 2016, con motivo de la rememoración del 59..$^{\circ}$ aniversario del fallecimiento de la poeta. Artículo disponible en http://www.elheraldo.hn/revistas/crimenes/918307-466/gabriela-mistral-poeta-diplom\%C3\%A1tica-y-nobel-de-literatura.

10 «Gabriela Mistral: única mujer iberoamericana que ha obtenido el Premio Nobel». Artículo sin fecha, disponible en http://cvc.cervantes.es/literatura/escritores/mistral/acerca/acerca_06.htm. 
Te acostaré en la tierra soleada con una

Dulcedumbre de madre para el hijo dormido,

Y la tierra ha de hacerse suavidades de cuna

Al recibir tu cuerpo de niño dolorido.

Luego iré espolvoreando tierra y polvo de rosas,

Y en la azulada y leve polvareda de luna,

Los despojos livianos irán quedando presos.

Me alejaré cantando mis venganzas hermosas,

¡Porque a ese hondor recóndito la mano de ninguna

Bajará a disputarme tu puñado de huesos! ${ }^{11}$

Su literatura despuntó por encima de las demás precisamente por su capacidad de elevarse del mundo circundante y de autorrecrearse una y otra vez: «Su mayor triunfo fue que, a través de su circunstancia de mujer, pudo trascender su propia personalidad y hacerse universal» (KocH, 1985: 729).

Pero, más allá de las intertextualidades e influencias mutuas entre las cuatro grandes poetas sudamericanas que la crítica ha puesto de manifiesto a lo largo de los años, el papel precursor de Delmira Agustini como adalid de la poesía femenina hispanoamericana se ha visto reforzado por las referencias a la autora de Los cálices vacíos que, de forma directa o indirecta, hicieron las propias Storni, Ibarbourou y Mistral en diferentes momentos de sus respectivas trayectorias literarias. Todas sin excepción aludieron públicamente a Agustini como fuente de inspiración y como referente necesario e ineludible.

Así, en el texto leído en el Instituto Vásquez Acevedo de Montevideo en 1938, con motivo del curso latinoamericano de vacaciones, un evento que, como ya hemos mencionado, reunió a las tres poetas del Cono Sur, Gabriela Mistral no quiso dejar pasar la ocasión de prestar homenaje a la gran lírica uruguaya, una alusión que hizo extensible también a María Eugenia Vaz Ferreira:

Recordaremos en primer lugar a nuestras dos grandes muertas, tan nuestras como vuestras, uruguayos. Pensaremos en Delmira Agustini, maestra de todas nosotras, raíz hincada más o menos en las que aquí estamos, y pensaremos a María Eugenia, alma heroica y clásica, y en lo heroico y en lo clásico hubiera querido pastorearnos a todas, pero que se nos fue demasiado pronto. $(\text { Gabriela Mistral })^{12}$

Del mismo modo, en una carta enviada a la poeta uruguaya Luisa Luisi, publicada por el periódico El imparcial de Montevideo el día 6 de febrero de 1926, Mistral le agradece la rea-

${ }^{11}$ Mistral, Gabriela, «Los sonetos de la muerte» (soneto I), disponible en http://amediavoz.com/mistral.htm\# $1^{\circ}$.

${ }^{12}$ Fragmento extraído de la conferencia leída por Gabriela Mistral en el Instituto Vásquez Acevedo (Montevideo) en enero de 1938, con ocasión del curso latinoamericano de vacaciones, disponible integralmente en http://www.cervantesvirtual.com/obra/texto-leido-por-gabriela-mistral-en-el-instituto-vasquez-acevedo-con-ocasion-del-curso-latinoamericano-de-vacaciones-realizado-en-montevideo-uruguay-en-1938--1/. 
lización del estudio que aquella ha elaborado sobre Agustini ${ }^{13}$, un ensayo que, en su opinión, contribuiría a ubicar a Delmira en el lugar merecido:

[...] Al fin se ha dicho de Delmira lo que debía decirse: su sitio magno, que casi no cede ni al de Rubén; el genio, así, sin miedo, el genio, y la vida de pasión pero no de vicio. Cuantas mujeres amamos la gran memoria de ella le agradecemos a usted su estudio noble y lento desde la raíz del alma. (Gabriela Mistral) $)^{14}$

A su vez, Alfonsina Storni pronunció una conferencia integralmente dedicada a Agustini en el Paraninfo de la Universidad de Montevideo el día 12 de enero de 1920. El texto de la mencionada ponencia fue posteriormente publicado por entregas en la sección literaria del diario independiente y de tendencia anarquista La noche, editado en Montevideo entre 1919 y 1923. La sección literaria del citado diario estuvo dirigida, entre finales de noviembre de 1919 y finales de abril de 1920, por Juana de Ibarbourou, lo que nos permite hacernos una idea del funcionamiento y alcance de las redes culturales que se tejieron entre las grandes poetas sudamericanas en las primeras décadas del siglo XX.

El texto integral de la conferencia dictada por Storni ha permanecido olvidado durante décadas, habiéndose entresacado de la misma tan solo fragmentos puntuales. ${ }^{15}$ No obstante, debido a la enorme relevancia del documento como testimonio del peso que tuvo la figura de Delmira Agustini como predecesora en la construcción de la identidad literaria de Storni, el texto ha sido recuperado en su totalidad y publicado por Elena Romiti en su obra Las poetas fundacionales del Cono Sur (2013).

El texto de Storni, en el que ensalza la figura de Agustini y realiza un breve recorrido crítico por su obra, se publicó en siete entregas (siete días sucesivos) en La noche, concretamente entre el 13 y el 19 de enero de 1920. La primera parte estuvo precedida por una breve introducción a cargo de Juana de Ibarbourou en la que la autora de Las lenguas de diamante, además de presentar el tema, lo resumía en diez puntos. Reproducimos a continuación la primera parte de la citada introducción:

Más abajo — consecuentes con la promesa formulada ayer — insertamos la primera parte de la brillante conferencia que sobre la personalidad de Delmira Agustini, leyó ayer en la Universidad Alfonsina Storni.

La gran poetisa, en su conferencia, hizo una defensa moral de Delmira Agustini, comparando la síntesis humana a una superposición de planos: abajo el mundo material trabajando como un peón oscuro y fiel, y recubriendo este mundo limitado el espíritu, que irradia hacia el infinito y escapa a la palabra. (Ibarbourou, 1920: 4)

${ }_{13}$ Dicho estudio abre la edición del volumen titulado Poesías de Delmira Agustini, preparado por Ovidio Fernández Ríos y publicado en Montevideo en 1944 por la editorial Claudio García \& Cía.

${ }^{14}$ Cita recogida en la página 47 de la revista Atlántida, publicada el 8 de julio de 1926 en Buenos Aires. La cita forma parte de un reportaje titulado «Se ha cumplido el duodécimo aniversario del fallecimiento de Delmira Agustini», que rinde homenaje a la autora de Los cálices vacíos. No figura el nombre en dicho ejemplar el nombre del autor del artículo.

15 Uno de los fragmentos de la referida conferencia ilustra también el reportaje publicado en la revista Atlántida a la que hemos aludido en la nota anterior. 
En efecto, Storni comenzó su ponencia realizando una acérrima defensa de Agustini y criticando a quienes la censuraron en su momento:

[...] cuando Delmira Agustini murió, de tan trágica y sensible manera, un velo espeso, una sombra opaca, un murmullo condenatorio para la mujer, pareció apagar un tanto el brillo de su obra. Este choque agudo de la sensibilidad contra la brutal naturaleza humana, esa repulsión instintiva del defectuoso hacia el defecto ajeno, hacia el defecto desnudo, hacia el error, o el aparente error que se hace público, es una de las cosas más trágicas de la vida.

[...] ¿Qué nos importa de la materia de Delmira Agustini, que no tenemos siquiera el derecho de investigar, de juzgar, si su alma, si el plano superior de su síntesis humana era un cielo poblado de estrellas deslumbradoras que nos arrojaban también ese mismo sentido de la Eternidad? (Storni, 1920a: 4)

A continuación, trató de definir el temperamento poético de la autora de El libro blanco (Frágil) y de describir su atribulada poética:

Ella es la mujer de vigor orgánico prematuro que despierta exaltada a la vida y el misterioso mundo desconocido viene en forma de sueños e imágenes a su naturaleza extraordinaria. [...] Si este factor genésico careciera del complemento cerebral, su naturaleza no resultaría extraordinaria, pues se definiría en uno de los vulgares histerismos de que padecen con frecuencia las mujeres, pero combinado con un cerebro de excepción, se desvía en una exaltación luminosa hacia la palabra y cuaja en versos.

[...] Respira toda la obra de Delmira Agustini una feminidad atroz, desordenada, que se nutre continuamente y desesperadamente en la sensación. [...] La obra de Delmira Agustini quiere ser por momentos un ala blanca, ascender, rozar la divinidad del éter, pero en hilos sólidos esta ala blanca está atada a la tierra, arraigada en la ferocidad de su mundo material. (Storni, 1920b: 4)

Figura 1. 1. ${ }^{\text {a }}$ entrega de la conferencia de A. Storni sobre D. Agustini, con introducción de

J. de Ibarbourou. La noche, Diario independiente. Departamento de Referencia y Bibliografía de la Biblioteca Nacional de Uruguay

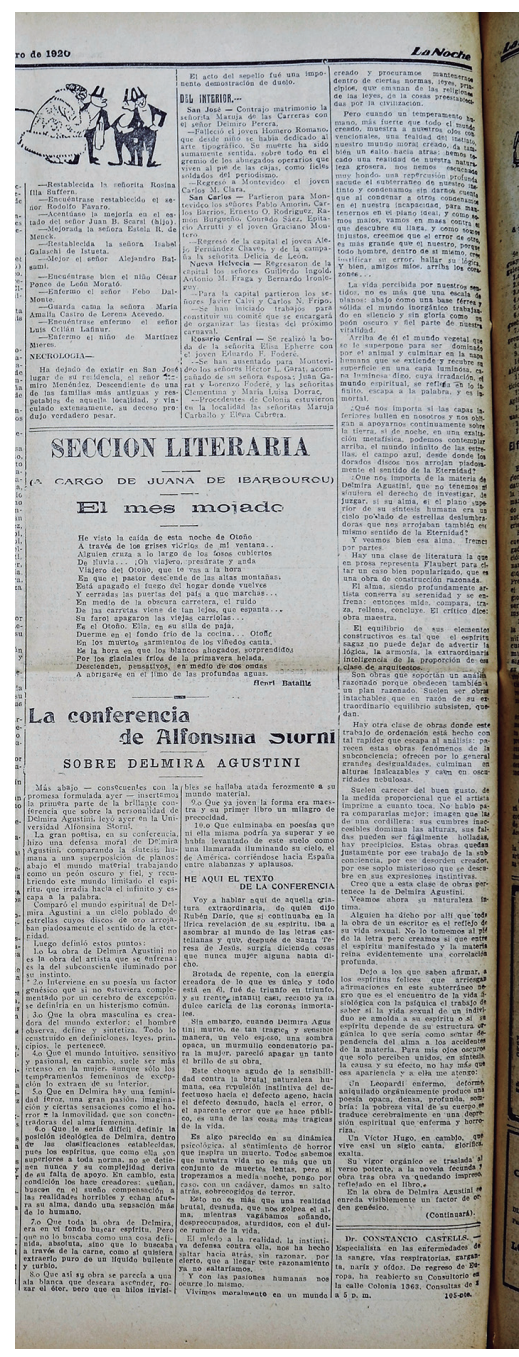

EPOS, XXXII (2016) págs. 71-84 
Por último, tras hacer un recorrido cronológico por los libros de versos de Agustini, comentando los poemas que, en su opinión, constituían lo mejor del legado de la uruguaya, Storni puso término a su conferencia lamentando la muerte prematura de Delmira, acaecida en el punto álgido de su capacidad creadora:

Acaso si hubiera llegado el reposo, el asiento de su naturaleza juvenil, hubiera podido extraer otros aspectos de su alma, pues de su gran capacidad poética, de su deslumbrante imaginación, todo podría esperarse.

Pero silenciada en plena primavera, solo nos queda el aferrarnos a sus libros de juventud y mirar admirados esa vitalidad profunda, esa carne inquietada por la sed del espíritu, este caer y levantarse continuo, esta feroz feminidad, avasallante, que la hizo producir una poesía nueva, desconocida, cálida, porque en la expresión viva de un temperamento humano excepcional, suerte de llamarada ardiente que se levantó como un volcán de este suelo, iluminó el cielo americano, se corrió hacia España y levantó en el mundo de habla castellana un sensacional rumor de admiración, de aplauso, de consagración.

Lejana, solita acaso en el entristecido cementerio, deshecha la carne luminosa, duerme y duerme [...] Ah, pobre criatura...que se le entró al cuerpo el frío de sus estatuas, la inmovilidad horrible de sus mármoles, el negro silencio de sus cuencas vacías y se le apagó en los ojos la luz clara y profunda... Nunca la amaremos bastante, amigos míos. (Storni, 1920c: 4).

También Juana de Ibarbourou, además de desempeñar un papel intermediario en la publicación en el diario independiente La noche del texto de Storni sobre Agustini, prestó su propio tributo a la figura de la insigne autora de Los cálices vacíos con un texto leído en el acto de homenaje celebrado en la «Casa del Arte» el día 6 de julio de 1928, al cumplirse el decimocuarto aniversario del fallecimiento de Delmira. Pocos días después, el citado texto fue publicado en la revista La pluma de Montevideo, dirigida por Alberto Zum Felde y editada por Orsini Bertani.

De la misma forma que Storni cerró su conferencia lamentando la temprana pérdida de Agustini, Ibarbourou comenzó su emocionada exposición aludiendo precisamente a esa triste circunstancia, y lo hizo insertando en su discurso algunos de los versos más célebres de su desdichada conterránea:

«Los cuervos negros sufren hambre de carne rosa» y es por eso que en plena juventud y en plena gloria, los callados cuervos de la muerte hicieron presa de aquella que fue un milagro ígneo y floral. ¡Oh, Delmira, santa Teresa nuestra, tan temprano dormida en «el gran lecho tendido de tristeza» que tú misma le pedías a Dios en la magnífica «Cuenta de sombra» de tu «Rosario de Eros»! (Ibarbourou, 1928: 35)

La autora de Las lenguas de diamante dedicó el resto de su discurso al enaltecimiento de la elegíaca personalidad poética de Agustini e hizo especial hincapié en la influencia que esta había ejercido y seguía ejerciendo sobre ella y sobre las demás poetas del continente americano:

[...] ¡ con cuánto fervor nos inclinamos ante esa figura a la vez dulce y sobrehumana, que será siempre la más alta, y de la cual venimos todas las que volcamos en el verso el pesado secreto de nuestros corazones! 
Delmira Agustini es la santa laica de las mujeres latinas que hacen poesía. Preside con su sombra tutelar el grupo ya tan compacto de las poetisas americanas. Como hacia a una hermana mayor se vuelven a ella todas las pupilas femeninas cargadas de ensueños. (Ibarbourou, 1928: 35)

Asimismo, Juana de Ibarbourou puso de manifiesto en su texto el carácter místico e incorpóreo de Agustini, cuya breve existencia terrenal había tenido, en su opinión, algo de sobrenatural:

Hay en la poesía de Delmira algo que no está en la sustancia humana. En ella, por fuerza, se habría realizado una trasmigración superior. Estudiándola nos envuelve una atmósfera de misterio. [...] Hubo un cuerpo que en las cifras humanas se llamó Delmira Agustini; pero estoy segura [de] que ese cuerpo fue solo el vaso de arcilla que contuvo una esencia astral sin nombre terrestre, pero que se nos hizo visible desde el verso. (Ibarbourou, 1928: 35-36)Además de este discurso público, existe en la Colección Juana de Ibarbourou que, al igual que la de Delmira, se custodia en el Departamento de Investigaciones y Archivo Literario de la Biblioteca Nacional de Uruguay, un poema inédito cuyo título temático, «Visión de Delmira», nos remite a la imagen que la poeta oriunda de Melo tenía de su predecesora y que, indirectamente, nos da cuenta también de la fuerte influencia que Agustini habría tenido en la configuración de la identidad poética de «Juana de América». Reproducimos a continuación, el poema en su versión integral ${ }^{16}$ :

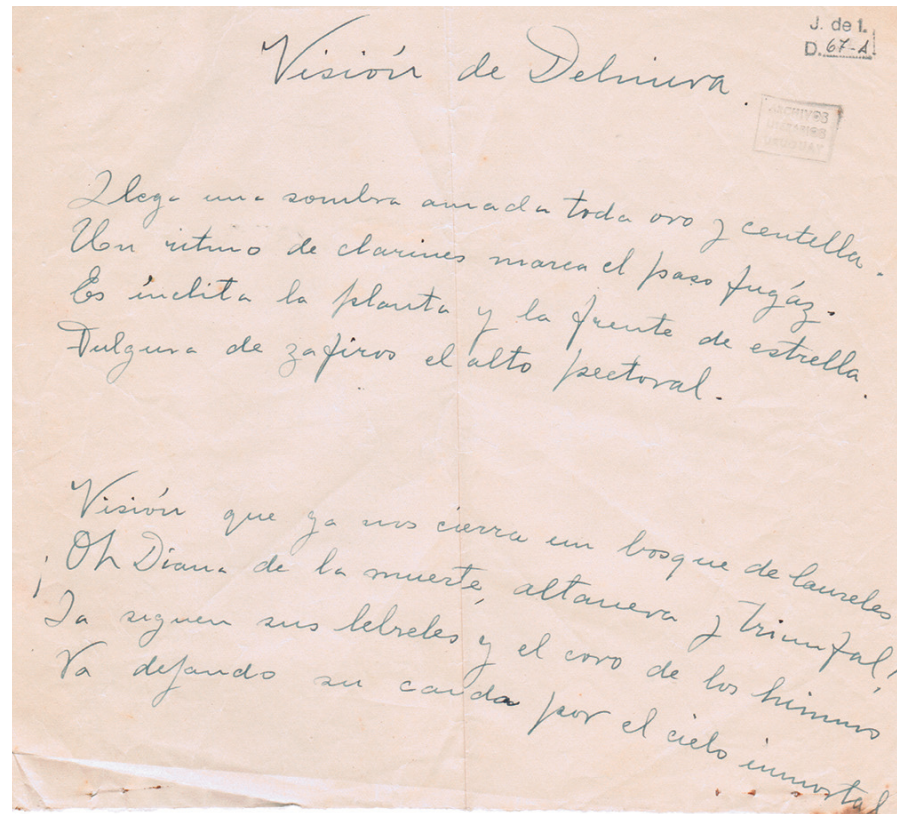

Figura 2. Autógrafo de «Visión de Delmira» (parte I). Colección Juana de Ibarbourou. Departamento de Investigaciones y Archivo Literario, Biblioteca Nacional de Uruguay

${ }^{16}$ Cabe señalar que en la reproducción del poema hemos intervenido textualmente en aspectos que atañen a la acentuación y a la puntuación, adaptando, de este modo, el texto a las normas de ortografía actualmente vigentes. 
Llega una sombra amada toda oro y centella.

Un ritmo de clarines marca el paso fugaz.

Es ínclita la planta y la frente de estrella.

Fulgura de zafiros el alto pectoral.

Visión que ya nos cierra un bosque de laureles

¡Oh, Diana de la muerte, altanera y triunfal!

La siguen sus lebreles y el coro de los himnos

Va dejando su candor por el cielo inmortal.

Cien flechas de diamante cayeron de su aljaba

Cien tórtolas insignes heridas de rubí

Pero ya está en la selva negra y enmarañada

Tendemos el oído, temblando, a su ¡alalí!

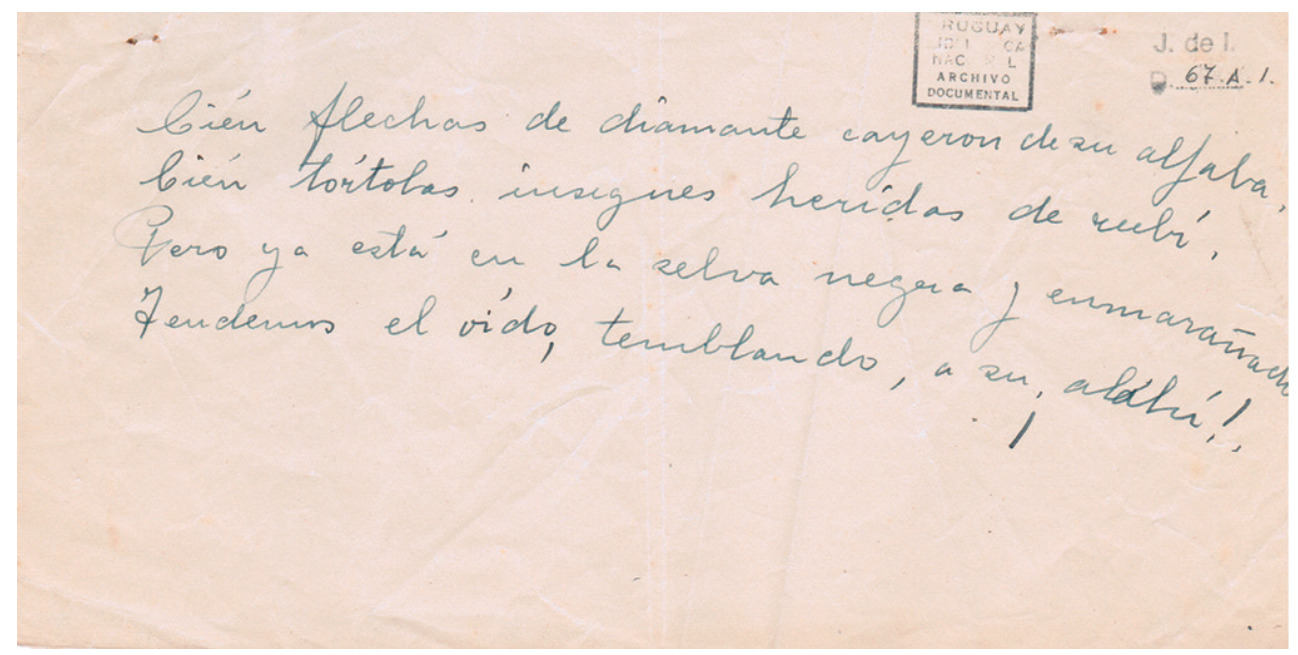

Figura 3. Autógrafo de «Visión de Delmira» (parte II). Colección Juana de Ibarbourou. Departamento de Investigaciones y Archivo Literario, Biblioteca Nacional de Uruguay

Pese a que el documento carece de fecha, Elena Romiti (2013: 155) se aventura a ubicarlo temporalmente en la primera etapa de la producción literaria de Ibarbourou, debido a la nitidez y emergencia con las que se le presenta a la autora de Las lenguas de diamante la imponente figura de Delmira.

En esta composición, Ibarbourou identifica a Delmira con la diosa romana Diana, una de las «vírgenes blancas», hija de Júpiter y Latona y hermana melliza de Apolo. La imagen de Diana se ha vinculado tradicionalmente a la de la mujer fuerte, hermosa, salvaje y libre, por lo que la simbiosis Diana/Delmira es especialmente significativa: «[...] esta es la Delmira de Juana, la imagen que de la primera tiene la segunda» (RoMiti, 2013: 155). 
La «visión» de Agustini emerge, así, del inconsciente de Ibarbourou como una presencia enérgica y selvática cuyo poder se manifiesta a través de la proliferación de imágenes visuales y auditivas que contiene el poema: el espíritu textualmente materializado de Delmira no pasa ni pretende pasar desapercibido, sino que, por el contrario, se manifiesta en toda su plenitud, dejando a su paso, tras difuminarse, ecos sonoros de su magnética aparición.

En conclusión, en este artículo hemos tratado de poner de manifiesto cómo, más allá de las coincidencias intertextuales, temáticas y vitales existentes entre las cuatro grandes poetas del Cono Sur (Delmira, Alfonsina, Juana y Gabriela), concomitancias que han sido apuntadas por la crítica a lo largo del último siglo, las tres últimas hicieron públicamente referencia, en diferentes momentos de sus respectivas trayectorias literarias, a la significativa influencia que la primera había ejercido sobre ellas, no solo en lo concerniente a la configuración de su poética sino también en lo tocante a la construcción de sus personalidades literarias, excéntricas y, en ese sentido, casi marginales, por su condición de mujeres en un territorio, el de la literatura, tradicionalmente ocupado por hombres.

\section{BIBLIOGRAFÍA}

Agustini, Delmira (1907): El libro blanco, Montevideo, O. M. Bertani.

- (1913): Los cálices vacíos, Montevideo, O. M. Bertani.

- (1944): Poesías, Montevideo, Claudio García \& Cía (edición de Fernández Ríos, Ovidio, con estudio de Luisi, Luisa).

- (s/d): «El intruso». Poema recuperado de http://cvc.cervantes.es/literatura/escritores/agustini/ antologia/intruso.htm.

Arbeleche, Jorge (1998): «Tres mujeres tristes», s/p. Artículo recuperado de http://www.mec.gub.uy/ academiadeletras/Boletines/03/Arbeleche.htm.

De Ibarbourou, Juana (1920): «Introducción a la conferencia de Alfonsina Storni sobre Delmira Agustini», sección literaria de La noche, Diario independiente, pág. 4, 13 de enero de 1920, Montevideo.

- (1928): «Discurso de homenaje a Delmira Agustini», La pluma, Revista mensual de Ciencias, Artes y Letras, volumen 7, pp. 35-36, julio de 1928, Montevideo.

- (1999): Las lenguas de diamante, Madrid, Torremozas (con prólogo de Puentes de Oyenard, Silvia).

- (s/d): «Rebelde». Poema recuperado de http://amediavoz.com/ibarbourou.htm\#REBELDE.

De Matamoro, Blas (s/d): «Alfonsina, la precursora», Biblioteca Virtual Miguel de Cervantes, s/p. Artículo recuperado de http://cvc.cervantes.es/actcult/storni/acerca/matamoro.htm.

Koch, Dolores (1985): «Delmira, Alfonsina, Juana y Gabriela», Revista Iberoamericana, volumen LI, número 132-133, pp. 723-729, julio-diciembre de 1985. Artículo recuperado de http://revista-iberoamericana.pitt.edu/ojs/index.php/Iberoamericana/article/view/4098/4267.

Macías, Sergio (s/d): «Gabriela Mistral: única mujer iberoamericana que ha obtenido el Premio Nobel», Biblioteca Virtual Miguel de Cervantes, s/p. Artículo recuperado de http://cvc.cervantes. es/literatura/escritores/mistral/acerca/acerca_06.htm.

Mistral, Gabriela (1926): «Carta a Luisa Luisi», El imparcial, 6 de febrero de 1926, Montevideo.

- (1938): «Texto leído por Gabriela Mistral en el Instituto Vásquez Acevedo, con ocasión del curso latinoamericano de vacaciones, realizado en Montevideo, Uruguay, en 1938», Biblioteca Virtual Miguel de Cervantes, s/p. Transcripción recuperada de http://www.cervantesvirtual.com/obra/ 
texto-leido-por-gabriela-mistral-en-el-instituto-vasquez-acevedo-con-ocasion-del-curso-latinoamericano-de-vacaciones-realizado-en-montevideo-uruguay-en-1938--1/.

Mistral, Gabriela (s/d): «Los sonetos de la muerte» (soneto I). Poema recuperado de http://amediavoz.com/mistral.htm\#1. .

N/A (1924): «Se ha cumplido el duodécimo aniversario del fallecimiento de Delmira Agustini», Atlántida, pág. 47, 8 de julio de 1924, Buenos Aires.

Pinto, Mercedes (1935): «Cuatro poetisas uruguayas», Revista Cubana, números 10, 11 y 12, pp. 4681, octubre-diciembre de 1935, La Habana.

Pueyerredón, Victoria (1978): «De Juanita Fernández a Juana de América», Boletín de la Asociación Europea de Profesores de Español, año X, número 18, pp. 133-136, marzo de 1978. Artículo recuperado de http://cvc.cervantes.es/Ensenanza/biblioteca_ele/aepe/pdf/boletin_18_10_78/boletin_18_10_78_18.pdf.

Rocca, Pablo (2011): Juana de Ibarbourou: las palabras y el poder, Colección Bordes \& Desbordes, número 2, Montevideo, Yaugurú.

Romiti, Elena (2013): Las poetas fundacionales del Cono Sur, Montevideo, Departamento de Investigaciones de la Biblioteca Nacional de Uruguay.

Storni, Alfonsina (1920a): «La conferencia de Alfonsina Storni sobre Delmira Agustini» (entrega I), sección literaria de La noche, Diario independiente, pág. 4, 13 de enero de 1920, Montevideo.

- (1920b): «La conferencia de Alfonsina Storni sobre Delmira Agustini» (entrega II), sección literaria de La noche, Diario independiente, pág. 4, 14 de enero de 1920, Montevideo.

- (1920c): «La conferencia de Alfonsina Storni sobre Delmira Agustini» (entrega VII), sección literaria de La noche, Diario independiente, pág. 4, 19 de enero de 1920, Montevideo.

- (s/d): «Hombre pequeñito». Poema recuperado de http://cvc.cervantes.es/actcult/storni/antologia/ antologia06.htm.

- (s/d): «Tú me quieres blanca». Poema recuperado de http://cvc.cervantes.es/actcult/storni/antologia/antologia03.htm.

\section{Fondos documentales y otras fuentes}

Colección Delmira Agustini. Departamento de Investigaciones y Archivo Literario de la Biblioteca Nacional de Uruguay.

Colección Juana de Ibarbourou. Departamento de Investigaciones y Archivo Literario de la Biblioteca Nacional de Uruguay.

Departamento de Referencia y Bibliografía de la Biblioteca Nacional de Uruguay.

Uruguay Educa: portal educativo de Uruguay, sitio web alojado en www.uruguayeduca.edu.uy. 